\title{
Low Prevalence of Antibodies Against Toxoplasma gondii in Chinese Populations
}

\author{
Shilin Xin, Ruijing Su, Nan Jiang, Longxian Zhang and Yurong Yang* \\ College of Animal Science and Veterinary Medicine, Henan Agricultural University, Zhengzhou, China
}

Toxoplasma gondii has been found to infect almost all warm-blooded animals, including humans. In this study, a total of 3,275 human serum samples were collected from hospitals in five provinces of China. About 5.13\% (168/3,275) $(95 \% \mathrm{Cl}, 4.42-5.94)$ of the serum samples tested positive for T. gondii lgG antibody by a modified agglutination test (MAT) (cut-off: 1:20). Significant associations were detected between geographic location $(O R=1.763)$, age $(O R=3.072)$, infertility in women $(O R=2.4409)$ and $T$. gondii infection in humans $(p<0.05)$. To minimize infection, citizens need to be informed about the best practices for toxoplasmosis prevention, including eating well-cooked meat, drinking boiled water, washing vegetables and fruits, and being careful during contact with cats.

\section{OPEN ACCESS}

Edited by:

Rafael Calero-Bernal,

Complutense University of Madrid, Spain

Reviewed by:

Antonio M. Mendes,

Universidade de Lisboa, Portugal Jacek Sroka,

National Veterinary Research Institute (NVRI), Poland

*Correspondence: Yurong Yang yangyu7712@sina.com

Specialty section:

This article was submitted to

Clinical Microbiology,

a section of the journal

Frontiers in Cellular and Infection Microbiology

Received: 15 January 2020 Accepted: 20 May 2020 Published: 23 June 2020

Citation:

Xin S, Su R, Jiang N, Zhang $L$ and Yang Y (2020) Low Prevalence of Antibodies Against Toxoplasma gondii in Chinese Populations.

Front. Cell. Infect. Microbiol. 10:302. doi: 10.3389/fcimb.2020.00302
Keywords: Toxoplasma gondii, seroepidemiology, risk factors, human, modified agglutination test, China

\section{INTRODUCTION}

Toxoplasma gondii is a ubiquitous protozoan parasite that is estimated to infect one-third of the human population worldwide. It can infect many species of warm-blooded animals, and is a significant zoonotic and veterinary pathogen. Members of the felid family, which are the definitive hosts of $T$. gondii, shed oocysts in their feces, and other warm-blooded animals may be intermediate hosts (Weiss and Dubey, 2009; Dubey, 2010; Torrey and Yolken, 2013). There are three primary routes from which people become infected with T. gondii: (1) by ingesting uncooked meat containing T. gondii tissue cysts; (2) by ingesting water, soils, vegetables and fruits contaminated by the feces of infected felids; and (3) transmission from the mother to the fetus via the placenta during pregnancy (Dubey, 1994; Montoya and Liesenfeld, 2004).

Toxoplasma gondii infection can become severe in people with AIDS, cancer, and organ transplants, and is usually asymptomatic in people with healthy immune systems (Dubey, 2010). In pregnant women, primary infection during pregnancy can lead to congenital infection of the fetus and newborn, resulting in severe damage, including stillbirth, miscarriage, and ocular toxoplasmosis (Montoya and Liesenfeld, 2004). Therefore, as a foodborne parasite, T. gondii infection has become a major potential public health problem worldwide.

Toxoplasma gondii is prevalent in most areas of the world, and people seropositive for $T$. gondii have been found in different regions (Tenter et al., 2000; Sukthana, 2006). The first human case of toxoplasmosis in China was reported in 1964 (Xie, 1964). Furthermore, some nationwide epidemiological surveys on T. gondii revealed that the in recent years, seropositive rate has been on the rise (1983: 5.20\%, 2001-2004: 7.97\%, 2000-2017: 8.22\%) (Lv, 2002; Xu et al., 2005; Pan et al., 2017; Dong et al., 2018). The purpose of this study was to further estimate the T. gondii infection rate in humans, and to study the effects of geographical, age, gender, pregnancy status, healthy conditions, and nursing on the seroprevalence of this disease. 


\section{MATERIALS AND METHODS}

\section{Participants and Serum Samples}

In this study, a total of 3,275 human serum samples were collected from hospitals in the Guangdong, Shanghai, Hubei, Guangxi, and Shaanxi regions of China from May 2018 to August 2019 (Table 1 and Figure 1). These serum samples were transported to the Henan Agricultural University (Zhengzhou, Henan, China) in cooler boxes for a survey of $T$. gondii infection. The age of participants ranged from newborn babies to the elderly, and other basic patient information was also collected. Unfortunately, the gender data information from children $(n=1847)$ were not available.

\section{Ethics Approval and Consent to Participate}

This study was carried out in accordance with the recommendations of the guidelines for Using Human and Animals Subjects by the Beijing Association for Science and Technology (SYXK [Beijing] 2007-0023). The sera were collected with the consent of patients or volunteers. Written consent was obtained from parents of all participating juveniles. This study was further approved by the ethics committee of the Henan Agricultural University (China).

\section{Serological Testing}

All of the serum samples were tested for antibodies against T. gondii by a modified agglutination test (MAT) (Dubey and Desmonts, 1987). Sera with MAT titers of 1:20 or higher were considered positive for T. gondii (Dubey, 2010; Yang et al., 2017). Whole formalin-treated T. gondii tachyzoites were obtained from the University of Tennessee Research Foundation (Knoxville, TN, USA; https://utrf.tennessee.edu/). T. gondii-positive mouse sera were provided by Dr. J. P. Dubey (Beltsville, ARS, USDA) as reference sera. All of the serum samples were tested at 1:20, after which the dilution was doubled to the maximum titer, and negative and positive controls were included in each plate.

\section{Statistical Analysis}

According the age data, the following categories were made: an older adult group, a young and middle-aged people group, and a children and juveniles group. Data from the five provinces were also sorted geographically into north vs. south, and coastal vs. inland (Figure 1 and Table 2). Furthermore, data were also analyzed and compared in terms of gender, weaning

TABLE 1 | Demographic characteristics and seroprevalence of Toxoplasma gondii in 3,275 participants.

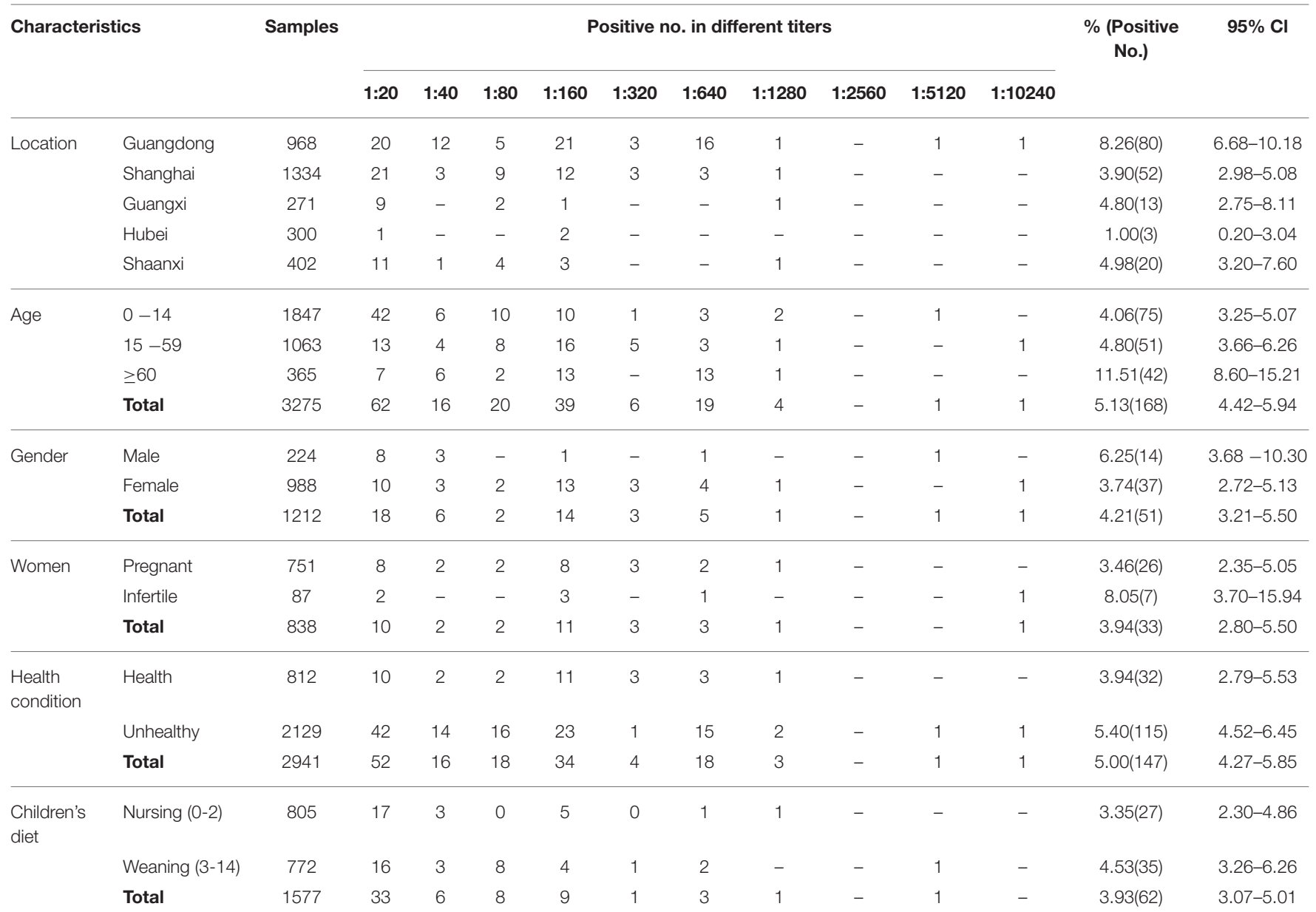



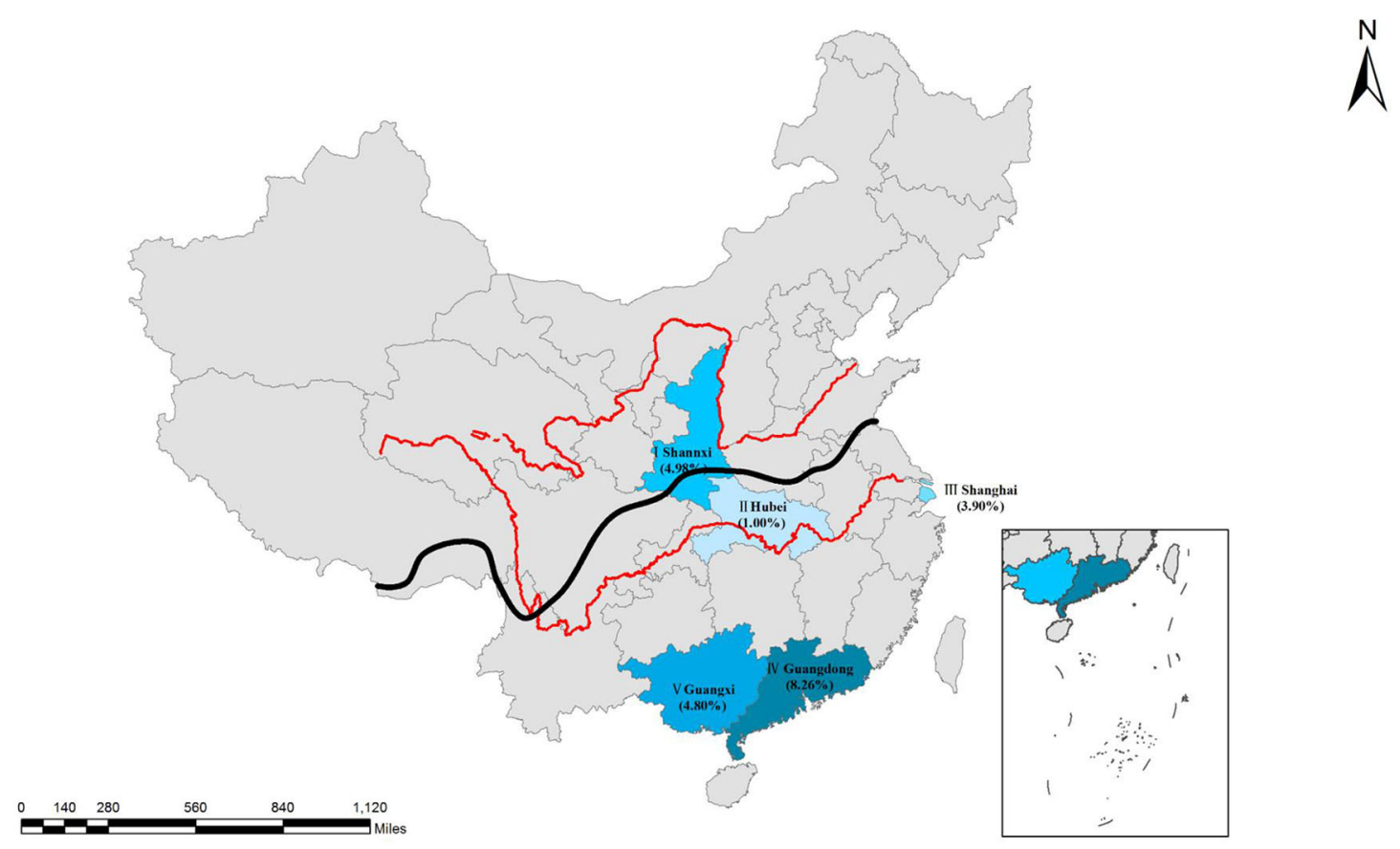

FIGURE 1 | Distribution of seroprevalence of T. gondii infection in Chinese populations. I, Shaanxi; II, Hubei; III, Shanghai, IV, Guangdong; V, Guangxi. Qinling Mountains-Huaihe River Line as the south and north of the boundary (The black line is shown in the figure). Red lines are showing the Yellow River and the Changjiang River. Map was adapted from Google earth.

and nursing. The 838 female participants (25-42 years old) were divided into pregnant and infertile categories. In addition, we defined participants who were clinically diagnosed with underlying diseases as unhealthy, and those who were not diagnosed with diseases as healthy (health physical examination). The classification standards of the above groups is summarized in Table 2.

Statistical analysis was performed using the GraphPad Prism 6.0 software (GraphPad Software Inc., San Diego, CA, USA). The results were analyzed by the Chi-square or Fisher's exact test and the Monte Carlo test of simulated data to assess the risk factors associated with T. gondii infection. A $p$-value of $<0.05$ was considered to be statistically significant.

\section{RESULTS}

\section{Seroprevalence of T. gondii in Humans and Risk Factor Analysis}

In this study, blood from 3,275 participants was evaluated for T. gondii infection. The results indicated that $5.13 \%(168 / 3,275)$ (95\% CI, 4.42-5.94) of the participants were seropositive for $T$. gondii by MAT, with titers of 1:20 in 62, 1:40 in 16, 1:80 in 20, $1: 160$ in $39,1: 320$ in six, $1: 640$ in $19,1: 1,280$ in four, 1:5,120 in one and 1:10,240 in one across the participants (Table 1).

All of the participants were divided into three age groups. The seroprevalence of $T$. gondii was $4.06 \%$ (75/1,847, 95\% CI, 3.25$5.07)$ for $0-14$ years old, $4.80 \%(51 / 1,063,95 \%$ CI, 3.66-6.26) for
15-59 years old, and $11.51 \%(42 / 365,95 \%$ CI, 8.60-15.21) for $\geq 60$ years old. Compared with the other two age groups, the prevalence of $T$. gondii infection was higher in the age group $\geq 60$ years, and the difference is very significant $(p<0.01)$, with an odds ratio of 3.072 (95\% CI, 2.068-4.565) (Tables 1, 2). Meanwhile, within the $0-14$ age group, the prevalence of $T$. gondii in the weaning group (3-14 years) $(4.53 \%, 35 / 772)$ was higher than that of the nursing group (0-2 years) $(3.35 \%$, $27 / 805)$, although the difference was not statistically significant $(p=0.2282)$.

In terms of gender, the seroprevalence of $T$. gondii in males $(6.25 \%, 14 / 224)$ was higher than that in females $(3.74 \%, 37 / 988)$ $(p=0.0980)$. The seroprevalence of T. gondii in infertile women $(8.05 \%, 7 / 87)$ was higher than in pregnant women $(3.46 \%$, $26 / 751$ ), and the difference was statistically significant ( $p=$ 0.0374 ), with an odds ratio of 2.4409 (95\% CI, 1.026-5.801). The seroprevalence of $T$. gondii was $5.40 \%(115 / 2,129)$ in the unhealthy group, which was higher than that of the clinically healthy group $(3.94 \%, 32 / 812)(p=0.1041$; Tables 1, 2).

When analyzed by geographic location, the seroprevalence of $T$. gondii varied by region. The seroprevalence of $T$. gondii infection was 5.15\% (95\% CI, 4.40-6.02) in Southern China, and 4.98\% (95\% CI, 3.20-7.60) in Northern China ( $p=0.8807)$. Additionally, the seroprevalence of $T$. gondii was significantly higher in coastal areas $(5.64 \%, 95 \% \mathrm{CI}, 4.81-6.60)$ than in inland areas $(3.28 \%, 95 \% \mathrm{CI}, 2.17-4.89)(p=0.0120)$, with an odds ratio of 1.763 (95\% CI, 1.126-2.760) (Tables 1, 2). 
TABLE 2 | Seroprevalence and risk factors for Toxoplasma gondii in participants tested by modified agglutination test.

\begin{tabular}{|c|c|c|c|c|c|}
\hline Variable & Classification standards & Samples & Seropositivity (\%) & $\begin{array}{l}\text { Odds ratio (95\% Confidence } \\
\text { internal) }\end{array}$ & $P$-value \\
\hline \multicolumn{6}{|l|}{ AGE } \\
\hline Older adults & $\geq 60$ years & 365 & 11.51 & 3.072 (2.068-4.565) & $0.0001^{*}$ \\
\hline Young and middle-aged people & $15-59$ years & 1063 & 4.80 & $1.191(0.8273-1.714)$ & 0.3975 \\
\hline Children and juveniles & $0-14$ years & 1847 & 4.06 & 1 & \\
\hline \multicolumn{6}{|l|}{ CHILDREN'S DIET } \\
\hline Weaning & 3-14 years & 772 & 4.53 & 1.368 (0.8199-2.284) & 0.2282 \\
\hline Nursing & $0-2$ years & 805 & 3.35 & 1 & \\
\hline \multicolumn{6}{|l|}{ GENDER } \\
\hline Male & - & 224 & 6.25 & $1.714(0.9098-3.227)$ & 0.0980 \\
\hline Female & - & 988 & 3.74 & 1 & \\
\hline \multicolumn{6}{|l|}{ WOMEN (25-42 YEARS) } \\
\hline Infertile & Abortion when embryo is $<12$ weeks, sterility & 87 & 8.05 & $2.4409(1.026-5.801)$ & $0.0374^{\star}$ \\
\hline Pregnant & Embryo is between 12 and 40 weeks & 751 & 3.46 & 1 & \\
\hline \multicolumn{6}{|l|}{ HEALTH CONDITION } \\
\hline Unhealthy & $\begin{array}{l}\text { Influenza, respiratory disease, diarrhea, fever, nephrosis, } \\
\text { infertile, and nervous system disease }\end{array}$ & 2129 & 5.40 & $1.392(0.9325-2.077)$ & 0.1041 \\
\hline Health & $\begin{array}{l}\text { Health physical examination personnel and without } \\
\text { apparent abnormality }\end{array}$ & 812 & 3.94 & 1 & \\
\hline \multicolumn{6}{|l|}{ GEOGRAPHICAL LOCATION } \\
\hline South & Shanghai, Guangdong, Guangxi and Hubei & 2873 & 5.15 & $1.037(0.6424-1.675)$ & 0.8807 \\
\hline North & Shaanxi & 402 & 4.98 & 1 & \\
\hline Coastal & Shanghai, Guangdong and Guangxi & 2573 & 5.64 & $1.763(1.126-2.760)$ & $0.0120^{*}$ \\
\hline Inland & Shaanxi and Hubei & 702 & 3.28 & 1 & \\
\hline
\end{tabular}

*Statistically significant.

\section{DISCUSSION}

The epidemiology of toxoplasmosis has been investigated in many countries, including China. The main detection methods for T. gondii include serological tests, PCR, isolation methods, and histopathology. Among them, serological tests are the most sensitive, rapid, and economical (Greiner and Gardner, 2000a,b; Hill et al., 2006; Dubey, 2008; Dard et al., 2016). However, serological tests vary in sensitivity, specificity, and predictive values (Cubas-Atienzar et al., 2019; Khan and Noordin, 2020). The Sabin-Feldman dye test (DT) is the most specific test for T. gondii, and it is considered the reference test for human diagnosis according to the World Health Organization (Sabin and Feldman, 1948). However, its main disadvantages are that it is labor-intensive and requires live parasites (dangerous). Thus, it was replaced by other tests in most laboratories (Dubey and Desmonts, 1987; Franck et al., 2008; Cubas-Atienzar et al., 2019; Khan and Noordin, 2020). The MAT was established by Dubey and was considered to be reliable after comparing several serological test methods with animal tissue biopsy results (Dubey et al., 1995a,b, 1996, 2015; Gamble et al., 2005; Hill et al., 2006; Gardner et al., 2010). The MAT has been extensively employed for detection of $T$. gondii antibodies in many species, including humans (Dubey, 2010).

In this study, we tested the serum of 3,275 participants by MAT, and the overall seroprevalence was $5.13 \%$. These results were lower than those of national surveys of $T$. gondii conducted between 2000 and 2017 (8.20\%) (Dong et al., 2018). This finding may be related to economic development and quality of life improvements, as people pay increasing attention to health and hygiene. In China, fully cooked food is more popular, and most people only drink boiled water and eat cooked meat, which greatly reduces the risk of $T$. gondii infection. The seroprevalence of $T$. gondii in humans in China is relatively low compared with other countries (Pappas et al., 2009; Dubey, 2010), a difference that may be explained by different dietary habits and other cultural habits. However, the seroprevalence of $5.13 \%$ in this survey indicated that humans from China are still widely exposed to T. gondii.

A significant increase in seroprevalence with age was demonstrated in this study, which is consistent with studies conducted in Egypt (Elsheikha et al., 2009), Northeast Brazil (Coêlho et al., 2003), and Nigeria (Kamani et al., 2009). This finding indicated that most $T$. gondii infections were obtained through postnatal transmission, and that accumulated exposure during a person's lifetime leads to an increased probability of infection.

There are only a few reports of seroprevalence in young children (Dubey, 2010). The maternal IgG antibodies to T. gondii can be transferred from a mother to baby through colostrum or the placenta (Gross et al., 2000; Miller et al., 2003). Usually, the passively transferred maternal IgG disappears by 12 months 
TABLE 3 | Seroprevalence of T. gondii infection in humans from five provinces in China (2001-2017).

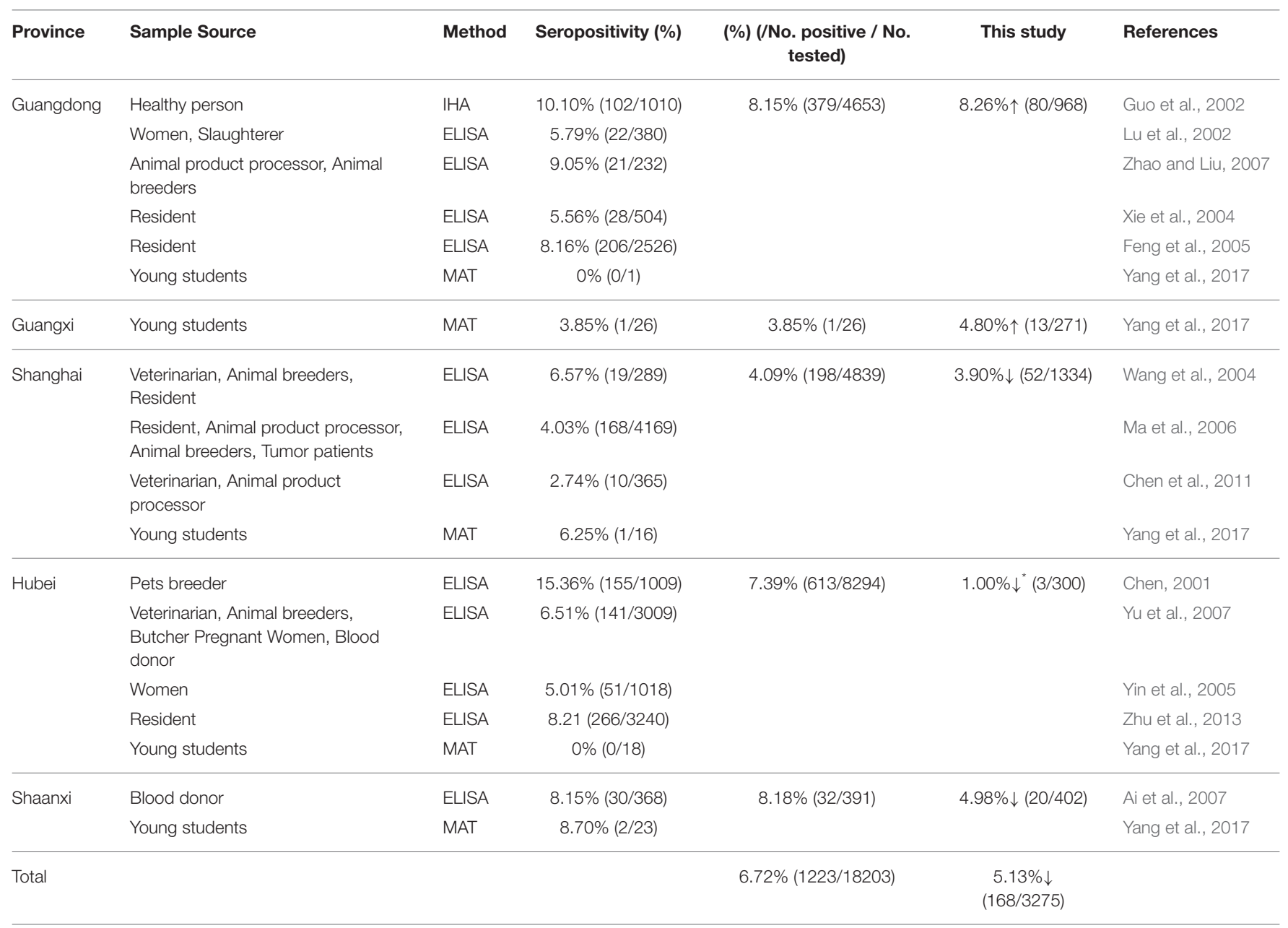

*Statistically significant, the seroprevalence of T. gondii infection in humans in this study compared to previously studies.

of age (Omata et al., 1994; Nielsen et al., 2005; Dubey, 2010). In this study, the prevalence of T. gondii IgG was $3.35 \%$ in nursing children, and two children (12 months) had high titers of 1:640 and 1:1280. Unfortunately, no follow-up studies have been conducted on nursing children, and we lack information about their mothers. It could not be ascertained if the $T$. gondii antibodies were passively transferred from the mothers or synthesized by the newborn child. However, congenital toxoplasmosis could not be ruled out in this survey.

In this study, human samples from five provinces were evaluated for $T$. gondii infection. We have summarized the available reports on human $T$. gondii infection from these provinces in Table 3. Here, the apparent seroprevalence was used to estimate the epidemiological regularity of $T$. gondii infection in humans. To obtain a clear picture of the true prevalence of T. gondii infection in China, in the future, the apparent seroprevalence needs to be estimated by Bayesian statistics for all unknown parameters (different sera, different serological test methods, and different test kits) (Basáñez et al., 2004). The present data were compared and interpreted to estimate the different levels of prevalence among similar populations. The total apparent seroprevalence of $T$. gondii was lower than of previous surveys (data from 2001 to 2017) $(p>0.05)$. In the Hubei province, the seroprevalence of T. gondii was significantly decreased compared to the survey results from 2001 to $2017(p<0.05)$. The difference may be related to the developed economy and hygiene, or to the limited number of samples $(n=300)$ collected from Hubei in this survey.

The seroprevalence of T. gondii in coastal areas (5.64\%) was significantly higher than that in inland areas (3.28\%). This may be explained by the subtropical monsoon climate, hot and humid climate, and lower altitudes in the coastal areas. Additionally, previous studies have shown that $T$. gondii oocysts can enter the ocean via rivers (Miller et al., 2002; Fayer et al., 2004; Dubey, 2010; Dong et al., 2018), that oocysts can be concentrated by filter-feeding invertebrates (Lindsay et al., 2001, 2004; Arkush et al., 2003), and that humans can be infected with T. gondii when they ingest undercooked shellfish or invertebrate predators. Furthermore, foreign food culture (undercooked steaks and vegetable salads) is more likely to affect residents of coastal areas, which tend to be more cosmopolitan than inland places. 
According to the different geographical locations, we found that the seroprevalence of T. gondii in humans from south China was slightly higher than in the north, which is consistent with the results of Yang et al. (2017). The reason for the north-south difference is unclear, but it has been reported that $T$. gondii infection is more prevalent in warm climates and high rainfall areas than that in cold and dry areas (Dubey, 2010).

When a pregnant woman is primarily infected with $T$. gondii, the fetus may be infected through the placenta and even cause death (Nowakowska et al., 2005). In this study, the seroprevalence of $T$. gondii in pregnant women was $3.46 \%$, within the range summarized by Gao et al. (2012), and lower than in some other countries such as Poland (40.6\%), Ethiopia (68.4\%) and Thailand (28.3\%) (Nissapatorn et al., 2011; Nowakowska et al., 2012; Agmas et al., 2015). Compared with pregnant women, the seroprevalence of $T$. gondii in infertile women was $8.05 \%$, and the difference was statistically significant. This finding is in agreement with others (Zhou et al., 2002; Dubey et al., 2014). There is indirect evidence indicating that chronic T. gondii infection may cause reproductive losses in small ruminants and mice (Dvorakova-Hortova et al., 2014; Hide et al., 2014). However, the relationship between chronic T. gondii infection and pregnancy problems in humans could not be firmly established, and more needs to be explored regarding human toxoplasmosis.

In addition, we found that men are more exposed to $T$. gondii infection than women; however, the differences were not significant. This result was consistent with the study by Yang et al. (2017), but contrary to the study by Xiao et al. (2010). Unfortunately, due to the lack of information, only a few participants were involved in the gender factor, so further investigation is necessary. The seroprevalence of $T$. gondii was higher in unhealthy people than in healthy people. This phenomenon was also found in humans and some animals (Tenter et al., 2000; Montoya and Liesenfeld, 2004; Dubey, 2008; Dong et al., 2018), which suggests that T. gondii infection may facilitate infection by other pathogens, or that unhealthy people may be more susceptible to T. gondii.

In addition, since the human sera were primarily collected from hospitals in this study, samples from asymptomatic humans was limited. More studies with larger sample sizes are necessary to confirm and extend the findings of this study.

\section{CONCLUSIONS}

Toxoplasma gondii infection is reported in Chinese citizens in this study, and that higher age, living in coastal areas, and infertility were related to $T$. gondii infection. It is necessary to monitor the prevalence of $T$. gondii in food animals and felids, and powerful and effective regulatory measures should be undertaken to reduce human exposure to T. gondii. These include inactivating $T$. gondii oocysts, drinking boiled water, and eating well-cooked meat. More preventive measures should be initiated to reduce the infection rate of $T$. gondii in humans, such as the distribution of leaflets, by physicians and in health education classes containing recommendations on the nature of this disease and its avoidance.

\section{DATA AVAILABILITY STATEMENT}

The datasets generated for this study are available on request to the corresponding author.

\section{ETHICS STATEMENT}

The studies involving human participants were reviewed and approved by Guideline for Using Subjects from Human and Animals by the Beijing Association for Science and Technology (SYXK [Beijing] 2007-0023). Written informed consent to participate in this study was provided by the participants' legal guardian/next of kin. Written informed consent was obtained from the individual(s), and minor(s)' legal guardian/next of kin, for the publication of any potentially identifiable images or data included in this article.

\section{AUTHOR CONTRIBUTIONS}

SX performed sample collection, laboratory tests, and contributed to the writing of the manuscript. RS and NJ performed sample collection and laboratory tests. LZ critically read and revised the manuscript. YY designed the study protocol, analyzed the results, and wrote the manuscript. All of the authors have read and approved the final version of the manuscript.

\section{FUNDING}

This study was funded by China Postdoctoral Science Foundation (NO. 2016M600577).

\section{ACKNOWLEDGMENTS}

We would like to thank Yujin Wang and Hongjie Ren (Henan Agricultural University, Zhengzhou, China) for helping with laboratory tests.

\section{REFERENCES}

Agmas, B., Tesfaye, R., and Koye, D. N. (2015). Seroprevalence of Toxoplasma gondii infection and associated risk factors among pregnant women in Debre Tabor, Northwest Ethiopia. BMC Res Notes 8:107. doi: 10.1186/s13104-015-1083-2

Ai, C. L., Hui, Q. F., Sun, X. M., Xue, Y. J., and Jing, C. X. (2007). Investigation and research on Toxoplasma gondii infection of blood donors in Yan'an city. Shaanxi Med J. 36, 884-886. doi: 10.3969/j.issn.1000-7377.2007.07.049

Arkush, K. D., Miller, M. A., Leutenegger, C. M., Gardner, I. A., Packham, A. E., Heckeroth, A. R., et al. (2003). Molecular and bioassay-based detection of Toxoplasma gondii oocyst uptake by mussels (Mytilus 
galloprovincialis). Int. J. Parasitol. 33, 1087-1097. doi: 10.1016/S0020-7519(03) 00181-4

Basáñez, M. G., Marshall, C., Carabin, H., Gyorkos, T., and Joseph, L. (2004). Bayesian statistics for parasitologists. Trends Parasitol. 20, 85-91. doi: 10.1016/j.pt.2003.11.008

Chen, C. Y. (2001). The study of individual having pet tend to Toxoplasma gondii infection. Chin. J. Zoonoses 17, 76-77. doi: 10.3969/j.issn.1002-2694.2001.01.027

Chen, Y., Li, Y., Zhang, W., Zhang, J. M., Tao, L. X., and Song, W. M. (2011). Infection and risk assessment of Toxoplasma gondii in key occupational groups in Fengxian district, Shanghai. Chin. J. Parasit. Dis. Cont. 6, 767-768. doi: 10.13350/j.cjpb.2011.10.023

Coêlho, R. A., Kobayashi, M., and Carvalho, L. B. Jr. (2003). Prevalence of IgG antibodies specific to Toxoplasma gondii among blood donors in Recife, Northeast Brazil. Rev. Inst. Med. Trop. São Paulo 45, 229-231. doi: 10.1590/S0036-46652003000400011

Cubas-Atienzar, A. I., Hide, G., and Smith, J. E. (2019). Mat seroprevalence infers low rates of Toxoplasma gondii in domestic pigs from Yucatan, Mexico. J. Parasitol. 105, 738-747. doi: 10.1645/18-188

Dard, C., Fricker-Hidalgo, H., Brenier-Pinchart, M. P., and Pelloux, H. (2016). Relevance of and new developments in serology for toxoplasmosis. Trends Parasitol. 32, 492-506. doi: 10.1016/j.pt.2016.04.001

Dong, H., Su, R., Lu, Y., Wang, M., Liu, J., Jian, F., et al. (2018), Prevalence, risk factors, and genotypes of Toxoplasma gondii in food animals and humans (2000-2017) from China. Front. Microbiol. 9:2108. doi: $10.3389 /$ fmicb. 2018.02108

Dubey, J. P. (1994). Toxoplasmosis. J. Am. Vet. Med. Assoc. 205, 1593-1598.

Dubey, J. P. (2008). The History of Toxoplasma gondii-the first 100 years. J. Eukaryotic Microbiol. 5, 467-475. doi: 10.1111/j.1550-7408.2008.00345.x

Dubey, J. P. (2010). Toxoplasmosis of Animals and Humans, 2nd ed. (Boca Raton, FL: CRC Press), 1-313.

Dubey, J. P., Andrews, C. D., Lind, P., Kwok, O. C., Thulliez, P., and Lunney, J. K. (1996). Antibody responses measured by various serologic tests in pigs orally inoculated with low numbers of Toxoplasma gondii oocysts. Am. J. Vet. Res. 57, 1733-1737.

Dubey, J. P., and Desmonts, G. (1987). Serological responses of equids fed Toxoplasma gondii oocysts. Equine Vet. J. 19, 337-339. doi: 10.1111/j.2042-3306.1987.tb01426.x

Dubey, J. P., Hotea, I., Olariu, T. R., Jones, J. L., and Dărăbuş G. (2014). Epidemiological review of toxoplasmosis in humans and animals in Romania. Parasitology 141, 311-325. doi: 10.1017/S0031182013 001509

Dubey, J. P., Lehmann, T., Lautner, F., Kwok, O. C., and Gamble, H. R. (2015). Toxoplasmosis in sentinel chickens (Gallus domesticus) in New England farms: seroconversion, distribution of tissue cysts in brain, heart, and skeletal muscle by bioassay in mice and cats. Vet. Parasitol. 214, 55-58. doi: 10.1016/j.vetpar.2015.09.004

Dubey, J. P., Thulliez, P., and Powell, E. C. (1995a). Toxoplasma gondii in Iowa sows: comparison of antibody titers to isolation of $T$. gondii by bioassays in mice and cats. J. Parasitol. 81, 48-53. doi: 10.2307/3284004

Dubey, J. P., Thulliez, P., Weigel, R. M., Andrews, C. D., Lind, P., and Powell, E. C. (1995b). Sensitivity and specificity of various serologic tests for detection of Toxoplasma gondii infection in naturally infected sows. Am. J. Vet. Res. 56, 1030-1036.

Dvorakova-Hortova, K., Sidlova, A., Ded, L., Hladovcova, D., Vieweg, M., Weidner, W., et al. (2014). Toxoplasma gondii decreases the reproductive fitness in mice. PLos ONE 9:e96770. doi: 10.1371/journal.pone.00 96770

Elsheikha, H. M., Azab, M. S., Abousamra, N. K., Rahbar, M. H., Elghannam, D. M., and Raafat, D. (2009). Seroprevalence of and risk factors for Toxoplasma gondii antibodies among asymptomatic blood donors in Egypt. Parasitol Res. 104, 1471-1476. doi: 10.1007/s00436-009-1350-Z

Fayer, R., Dubey, J. P., and Lindsay, D. S. (2004). Zoonotic protozoa: from land to sea. Trends Parasitol. 20, 531-536. doi: 10.1016/j.pt.2004.08.008

Feng, Y. J., Liu, X. N., Ren, W. F., Pan, Z. M., Gao, Y. P., and Guo, R. T. (2005). Serological analysis of toxoplasmosis in Guangzhou city in 2004. J Trop Med. 5, 830-831. doi: 10.3969/j.issn.1672-3619.2005.06.034
Franck, J., Garin, Y. J., Dumon, H. (2008). LDBio-Toxo II immunoglobulin G Western blot confirmatory test for anti-toxoplasma antibody detection. J. Clin. Microbiol. 46, 2334-2338. doi: 10.1128/JCM.00182-08

Gamble, H. R., Dubey, J. P., and Lambillotte, D. N. (2005). Comparison of a commercial ELISA with the modified agglutination test for detection of Toxoplasma infection in the domestic pig. Vet. Parasitol. 128, 177-181. doi: 10.1016/j.vetpar.2004.11.019

Gao, X. J., Zhao, Z. J., He, Z. H., Wang, T., Yang, T. B., Chen, X. G., et al. (2012). Toxoplasma gondii infection in pregnant women in China. Parasitology 139, 139-147. doi: 10.1017/S0031182011001880

Gardner, I. A., Greiner, M., and Dubey, J. P. (2010). Statistical evaluation of test accuracy studies for Toxoplasma gondii in food animal intermediate hosts. Zoonoses Public Health 57, 82-94. doi: 10.1111/j.1863-2378.2009.01281.x

Greiner, M., and Gardner, I. A. (2000a). Application of diagnostic tests in veterinary epidemiologic studies. Prev. Vet. Med. 30, 43-59. doi: 10.1016/S0167-5877(00)00116-1

Greiner, M., and Gardner, I. A. (2000b). Epidemiologic issues in the validation of veterinary diagnostic tests. Prev. Vet. Med. 30, 3-22. doi: 10.1016/S0167-5877(00)00114-8

Gross, U., Lüder, C. G., Hendgen, V., Heeg, C., Sauer, I., Weidner, A., et al. (2000). Comparative immunoglobulin $\mathrm{G}$ antibody profiles between mother and child (CGMC test) for early diagnosis of congenital toxoplasmosis. J. Clin. Microbiol. 38, 3619-3622. doi: 10.1128/JCM.38.10.3619-3622.2000

Guo, Y., Wang, S. Q., Jin, L. Q., and Chen, J. Q. (2002). Application of ELISA and IHA on detecting the antibodies against Toxoplasma gondii in the sera of humans in the Hilly Land of Meizhou in East Guangdong Province. Dis Surv. 17, 247-249. doi: 10.3784/j.issn.1003-9961.2002.07.006

Hide, G., Morley, E. K., Hughes, J. M., Gerwash, O., Elmahaishi, M. S., Elmahaishi, K. H., et al. (2014). Evidence for high levels of vertical transmission in Toxoplasma gondii. Parasitology 136, 1877-1885. doi: 10.1017/S0031182009990941

Hill, D. E., Chirukandoth, S., Dubey, J. P., Lunney, J. K., and Gamble, H. R. (2006). Comparison of detection methods for Toxoplasma gondii in naturally and experimentally infected swine. Vet. Parasitol. 141, 9-17. doi: 10.1016/j.vetpar.2006.05.008

Kamani, J., Mani, A. U., Egwu, G. O., and Kumshe, H. A. (2009). Seroprevalence of human infection with Toxoplasma gondii and the associated risk factors, in Maiduguri, Borno state, Nigeria. Ann. Trop. Med. Parasitol. 103, 317-321. doi: $10.1179 / 136485909 X 435094$

Khan, A. H., and Noordin, R. (2020). Serological and molecular rapid diagnostic tests for Toxoplasma infection in humans and animals. Eur. J. Clin. Microbiol. Infect. Dis. 39, 9-30. doi: 10.1007/s10096-019-03680-2

Lindsay, D. S., Collins, M. V., Mitchell, S. M., Welch, C. N., Rosypal, A. C., Flick, G. J., et al. (2004). Survival of Toxoplasma gondii oocysts in eastern oysters (Crassostrea virginica). J. Parasitol. 90, 1054-1057. doi: 10.1645/GE-296R

Lindsay, D. S., Phelps, K. K., Smith, S. A., Flick, G., Sumner, S. S., and Dubey, J. P. (2001). Removal of Toxoplasma gondii oocysts from seawater by eastern oysters (Crassostrea virginica). J. Eukaryot. Microbiol. Suppl: 197S-198S. doi: 10.1111/j.1550-7408.2001.tb00517.x

Lu, G. P., Zhou, Y. M., Zhou, C. H., and Wu, A. L. (2002). Study on the infection and control of Toxoplasma gondii in major population of Jiangmen city. J. Trop. Med. 2, 309-311. doi: 10.3969/j.issn.1672-3619.2002.03.038

Lv, Y. C. (2002). Recent research on the epidemiology of toxoplasmosis in China. Guangxi Med. J. 24, 48-52. doi: 10.3969/j.issn.0253-4304.2002.01.022

Ma, X. B., Cai, L., Zhang, B. X., Fu, Y. H., Chen, J, Cao, L., et al. (2006). A survey on Toxoplasma gondii infection of human in Shanghai. Shanghai J. Pre Med. 18, 483-486. doi: 10.3969/j.issn.1004-9231.2006.10.001

Miller, D. S., Faulkner, C., and Patton, S. (2003). Detection of Toxoplasma gondii IgG antibodies in juvenile great grey kangaroos, Macropus giganteus. J. Zoo Wildlife Med. 34, 189-193. doi: 10.1638/1042-7260(2003)034[0189:DOTGIA]2. $0 . \mathrm{CO} ; 2$

Miller, M. A., Gardner, I. A., Kreuder, C., Paradies, D. M., Worcester, K. R., Jessup, D. A., et al. (2002). Coastal freshwater runoff is a risk factor for Toxoplasma gondii infection of southern sea otters (Enhydra lutris nereis). Int. J. Parasitol. 32, 997-1006. doi: 10.1016/S0020-7519(02)00069-3

Montoya, J. G., and Liesenfeld, O. (2004). Toxoplasmosis. Lancet 363, 1965-1976. doi: 10.1016/S0140-6736(04)16412-X 
Nielsen, H. V., Schmidt, D. R., and Petersen, E. (2005). Diagnosis of congenital toxoplasmosis by two-dimensional immunoblot differentiation of mother and child immunoglobulin g profiles. J. Clin. Microbiol. 43, 711-715. doi: 10.1128/JCM.43.2.711-715.2005

Nissapatorn, V., Suwanrath, C., Sawangjaroen, N., Ling, L. Y., and Chandeying, V. (2011). Toxoplasmosis-serological evidence and associated risk factors among pregnant women in southern Thailand. Am. J. Trop Med. Hyg. 85, 243-247. doi: 10.4269/ajtmh.2011.10-0633

Nowakowska, D., Respondek-Liberska, M., Golab, E., Stray-Pedersen, B., Szaflik, K., Dzbenski, T. H., et al. (2005). Too late prenatal diagnosis of fetal toxoplasmosis: a case report. Fetal Diagn Ther. 20, 190-193. doi: $10.1159 / 000083903$

Nowakowska, D., Wujcicka, W., Sobala, W., Spiewak, E., Gaj, Z., and Wilczynski, J. (2012). Age-associated prevalence of Toxoplasma gondii in 8281 pregnant women in Poland between 2004 and. Epidemiol. Infect. 142, 656-661. doi: 10.1017/S0950268813001179

Omata, Y., Oikawa, H., Kanda, M., Mikazuki, K., Dilorenzo, C., Claveria, F. G., et al. (1994). Transfer of antibodies to kittens from mother cats chronically infected with Toxoplasma gondii. Vet. Parasitol. 52, 211-218. doi: 10.1016/0304-4017(94)90113-9

Pan, M., Lyu, C., Zhao, J., and Shen, B. (2017). Sixty years (1957-2017) of research on toxoplasmosis in China-an overview. Front. Microbiol. 8:1825. doi: $10.3389 /$ fmicb. 2017.01825

Pappas, G., Roussos, N., and Falagas, M. E. (2009). Toxoplasmosis snapshots: global status of Toxoplasma gondii seroprevalence and implications for pregnancy and congenital toxoplasmosis. Int. J. Parasitol. 39, 1385-1394. doi: 10.1016/j.ijpara.2009.04.003

Sabin, A. B., and Feldman, H. A. (1948). Dyes as microchemical indicators of a new immunity phenomenon affecting a protozoon parasite (Toxoplasma). Science 108, 660-663. doi: 10.1126/science.108.2815.660

Sukthana, Y. (2006). Toxoplasmosis: beyond animals to human. Trends Parasitol. 22, 137-142. doi: 10.1016/j.pt.2006.01.007

Tenter, A. M., Heckerotha, A. R., and Weissb, L. M. (2000). Toxoplasma gondii: from animals to humans. Int. J. Parasitol. 30, 1217-1258. doi: 10.1016/S0020-7519(00)00124-7

Torrey, E. F., and Yolken, R. H. (2013). Toxoplasma oocysts as a public health problem. Trends Parasitol. 29, 380-384. doi: 10.1016/j.pt.2013.06.001

Wang, W. Y., Liu, Y. N., Shen, H. G., Zhao, D. X., and Pan, J. Q. (2004). Investigation of Toxoplasma gondii infection in special occupations in Minhang district, Shanghai. Chin. J. Schistoso Cont. 16, 342. doi: 10.3969/j.issn.1005-6661.2004.05.028

Weiss, L. M., and Dubey, J. P. (2009). Toxoplasmosis: a history of clinical observations. Int. J. Parasitol. 39, 895-901. doi: 10.1016/j.ijpara.2009.02.004
Xiao, Y., Yin, J., Jiang, N., Xiang, M., Hao, L., Lu, H., et al. (2010). Seroepidemiology of human Toxoplasma gondii infection in China. BMC Infect. Dis. 10:4. doi: 10.1186/1471-2334-10-4

Xie, T. H. (1964). A case report of human toxoplasmosis. Jiangxi Med. J. 4:121.

Xie, X. Q., Deng, Y. H., Xiao, K. G., Huang, H. Q., Huang, J. P., Lu, J. W., et al. (2004). Study on the Toxoplasma gondii infection and its control in Meixian. J. Trop. Med. 4, 731-732. doi: 10.3969/j.issn.1672-3619.2004.06.027

Xu, L. Q., Chen, Y. D., and Sun, F. H. (2005). A national survey on current status of the important parasitic diseases in human population. Chin. J. Parasitol. Parasit. Dis. 23(5 Suppl):332-340. doi: 10.3969/j.issn.1000-7423.2005.z1.004

Yang, N., Wang, D., Xing, M., Li, C., Li, J., Wu, A., et al. (2017). Seroepidemiology and risk factors of Toxoplasma gondii infection among the newly enrolled undergraduates and postgraduate students in China. Front. Microbiol. 8:2092. doi: $10.3389 /$ fmicb.2017.02092

Yin, W. P., Mao, H. L., and Kong, X. L. (2005). Examining toxoplasmosis of 1018 women of child-bearing age. J. Public Health Prevent. Med. 16:57. doi: 10.3969/j.issn.1006-2483.2005.06.026

Yu, P. H., Chen, J. S., Zhang, H. X., Zhang, C., Wang, C. X., Mao, C. X., et al. (2007). The serological survy of Toxoplasma infection in Wuhan city. Chin. J. Zoonoses 23, 393-394. doi: 10.3969/j.issn.1002-2694.2007.04.023

Zhao, L. Q., and Liu, S. J. (2007). Serological surveillance of Toxoplasma gondii infection in Haizhu district in 2004. J. Trop. Med. 7, 495-496. doi: 10.3969/j.issn.1672-3619.2007.05.032

Zhou, Y. H., Lu, Y. J., Wang, R. B., Song, L. M., Shi, F., Gao, Q. F., et al. (2002). Survey of infection of Toxoplasma gondii in infertile couples in Suzhou countryside. Zhonghua Nan Ke Xue. 8, 350-352. doi: 10.3969/j.issn.1009-3591.2002.05.012

Zhu, J., Wei, R. H, Yang, S. G., and Zhu, M. S. (2013). Seroepidemiologic investigation on the infection of Toxoplasma gondii among population in Shiyan area. J. Hubei Univ. Med. 32, 199-200. doi: 10.7543/j.issn.1006-9674.2013.03.003

Conflict of Interest: The authors declare that the research was conducted in the absence of any commercial or financial relationships that could be construed as a potential conflict of interest.

Copyright (c) 2020 Xin, Su, Jiang, Zhang and Yang. This is an open-access article distributed under the terms of the Creative Commons Attribution License (CC BY). The use, distribution or reproduction in other forums is permitted, provided the original author(s) and the copyright owner(s) are credited and that the original publication in this journal is cited, in accordance with accepted academic practice. No use, distribution or reproduction is permitted which does not comply with these terms. 